Our Nature (2012) 10

\title{
Breeding behaviour of White-eared Bulbul Pycnonotus leucotis as observed in a house courtyard at Bikaner, Rajasthan
}

\author{
Meera Srivastava \\ P.G. Department of Zoology, Govt. Dungar College, Bikaner 334001 \\ Rajasthan, India. \\ meerayk@rediffmail.com
}

The White-eared Bulbul Pycnonotus leucotis is found mostly in the desert-dry lowlands from Afghanistan, Pakistan, Iraq, Iran, Bahrain, and in the northern parts of India. This bulbul has a medium gray body, jet black head; subtle rounded black crest and a distinct white patch over the ear coverts, hence the name. Feet and legs are mottled dark gray/brown.

These birds are sexually monomorphic. An adult is $18 \mathrm{~cm}$ (6-7 inches) long from tail tip to beak tip. The tail is jet black, with $1 / 8$ th to $1 / 4$ th inch white tips on the end of the feathers visible from above and below. Oddly, this bulbul, as with the white spectacled, sometimes called 'yellow-vented bulbul' $P$. xanthopygos has bright distinct yellow feathers in the vent area, visible only from below and behind.

The present observations were made in the courtyard situated in the city of Bikaner $\left(28^{\circ} \mathrm{N}\right.$ latitude and $73^{\circ} 18^{\prime} \mathrm{E}$ longitudes), Rajasthan, on a small Araucaria tree planted in a pot where the bulbul constructed its nest (Plate 1.). Both the male and female (Plate 2.) took part in the event. The clutch size was of two to three eggs (Plate 3.), which hatched in 14-15 days (Plate 4.). Female brought the feed for the young chicks which seemed to be always hungry (Plate 5.). The food generally comprised of small insects and their larvae which were seen to be picked up from the adjoining plantations. The chicks grew to their full in about 15 days (Plate 6.) after hatching. It was observed that the male took full interest in guarding the nest and the young ones. Red vented bulbul (Plate 7.) was among the intruders which tried to attack the nest besides the crows.

A significant finding was that the nest was reused by the adults for laying eggs. During the period of about two and a half months, the nest was used thrice by the same pair; first clutch size was of three while the following one had two eggs at a time. The first batch of young ones although hatched successfully (Plate 5.) were preyed upon by the crow but the chicks which hatched out from the subsequent two grew up to take flight (Plate 6.). 
Our Nature (2012) 10

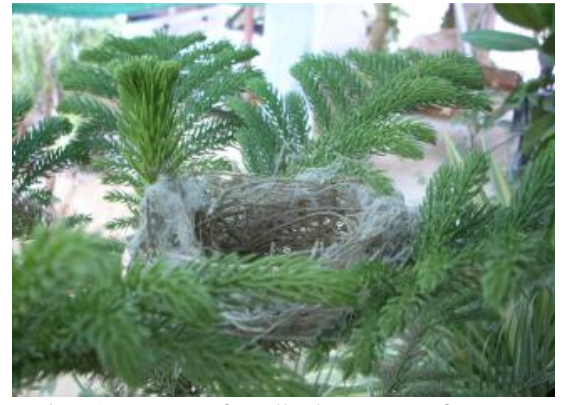

Plate1. Nest of Bulbul on tree of Araucaria

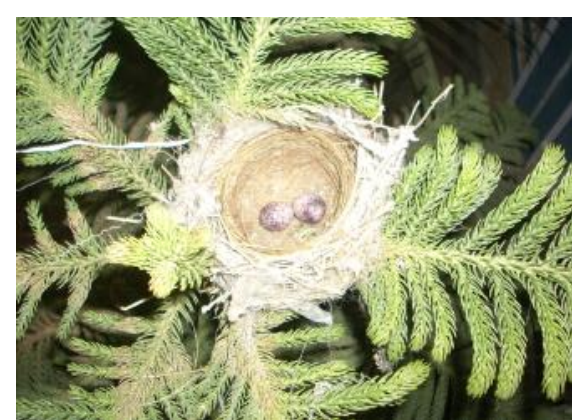

Plate 3. Eggs of Bulbul

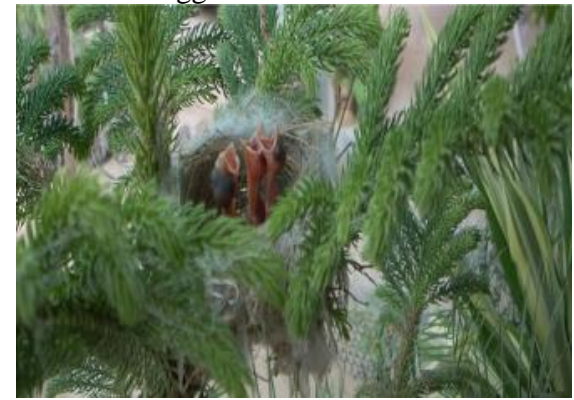

Plate 5. Chicks waiting for food

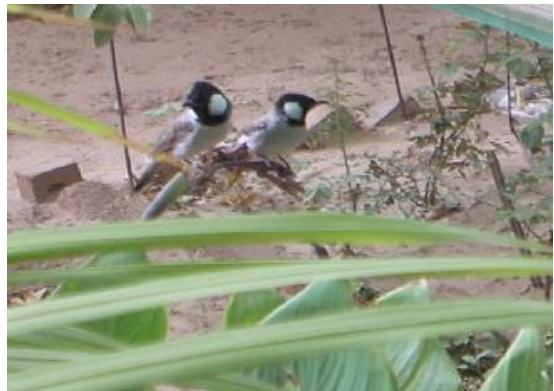

Plate 2.Male and female Bulbuls perched on a branch

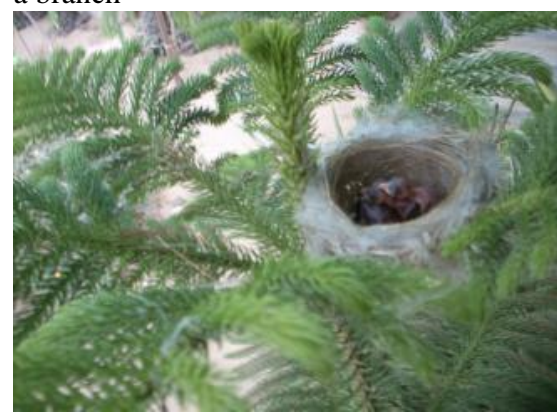

Plate 4. Young chicks in the nest

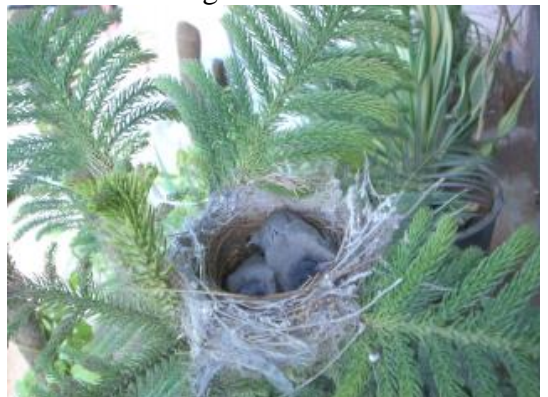

Plate 6. Full grown chicks

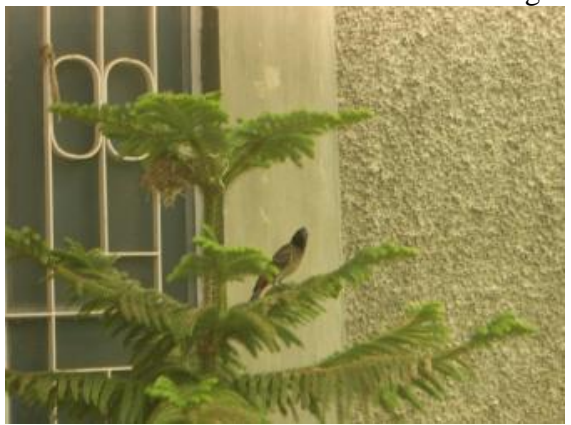

Plate 7. Red-vented bulbul- The intruder 